\title{
latrogenic Cushings Syndrome precipitated by fluticasone nasal drops in HIV infected patient
}

\author{
P Avari1, C Wills², K Moses², A Qureshi1
}

1Department of Endocrinology, Northwick Park Hospital, London North West Healthcare NHS Trust, UK

2Department for Infectious Diseases, Northwick Park Hospital, London North West Healthcare NHS Trust, UK

\section{INTRODUCTION}

- Ritonavir is a protease inhibitor commonly used in patients with human immunodeficiency virus (HIV) infections. It is also a potent inhibitor of cytochrome P450 3A4.

- Hepatic metabolism of inhaled corticosteroids takes place via cytochrome P450. Enzyme inhibitors, such as ritonavir, can interact with cytochrome P450, leading to an increase in the bioavailability of inhaled corticorticosteroids. This can result in an accumulation of the steroid drug and Cushing's syndrome.

\section{CASE HISTORY}

- A 43 year old Somali woman presented with increasing fatigue, difficulty getting out of her chair and $15 \mathrm{~kg}$ weight gain over one month.

- Past medical history included paranoid psychosis, human immunodeficiency virus (HIV) and nasal congestion due to adenotonsillar hypertrophy. She declined surgery and was commenced on inhaled Flixonase Nasule (Fluticasone 400 micrograms/unit dose) by her local GP as recommended in ENT clinic.

- Her HIV infection was well controlled (viral load <50RNA copies $/ \mathrm{ml}$ ), with excellent immunological reconstitution (CD4 count $>500$ cells $/ \mathrm{mm} 3$ ).

- Current medications include ritonavir/ darunovir, tenofovir, emtricitabine, flupenthixol depot, zopiclone, olanzapine, ferrous sulphate, folic acid and fluticasone nasal spray.

- On presentation, she had rounded facial facies, truncal adiposity, dorsocervical fat pad and extensive purple striae over the axillae, upper chest, breasts, groin and thighs.

\section{INVESTIGATIONS}

Blood pressure: $151 / 79 \mathrm{~mm} / \mathrm{Hg}$

Capillary blood glucose: $19.4 \mathrm{mmol} / \mathrm{L}$

Pituitary profile: prolactin 1033mIU/L; otherwise unremarkable

Low-dose dexamethasone suppression test: plasma cortisol $<28 \mathrm{nmol} / \mathrm{L}$ (normal range $<50 \mathrm{nmol} / \mathrm{L}$ )

24hour urinary free cortisol levels (x2): 28 and $12 \mathrm{nmol} / \mathrm{L}$ (normal range $<120 \mathrm{nmol} / 24 \mathrm{~h}$ ).

MRI pituitary: unremarkable
Drug Metabolism Occurs via Hepatic Cytochrome P450 Enzymes

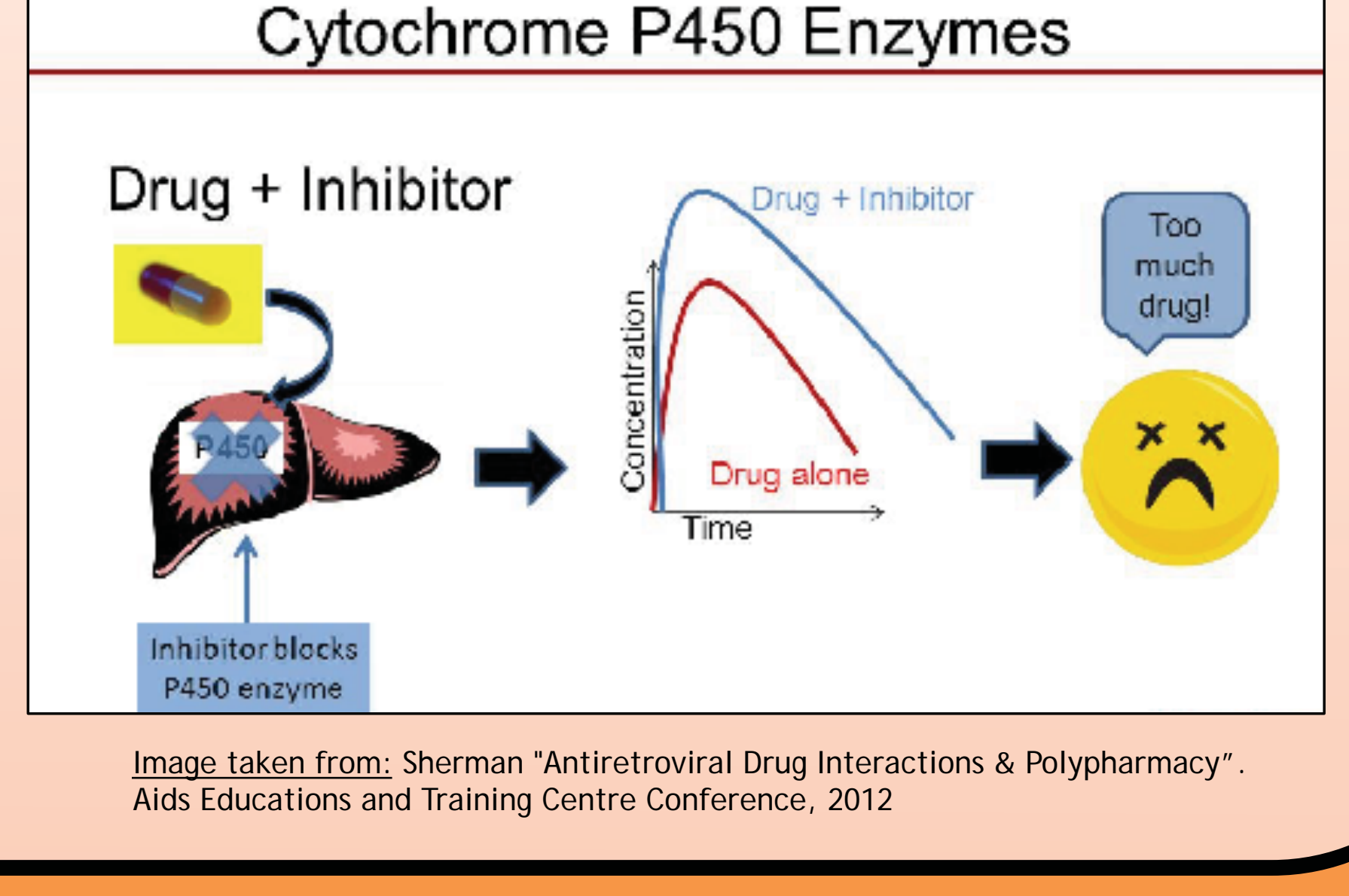

\section{TREATMENT}

- Her clinical presentation and results were consistent with glucocorticoid excess.

- A diagnosis of iatrogenic Cushing's syndrome was made secondary to high systemic steroid levels from inhaled fluticasone, induced by concomitant Ritonavir use.

- The hyperprolactinaemia was attributed to Olanzapine; a common dose-related side effect of antipsychotic treatment.

- Fluticasone inhalers were slowly weaned and her symptoms, blood pressure and glucose improved.

\section{DISCUSSION}

- latrogenic Cushing's is one of the leading causes of Cushing's syndrome.

- Fluticasone is a particularly potent inhaled steroid that has been commonly associated with iatrogenic Cushing's syndrome.

- Ritonavir is a potent inhibitor of the cytochrome P450 enzyme CYP3A4 and increases levels of drugs metabolized through the CYP3A pathway.

- Endocrine test results in iatrogenic Cushing's may not be abnormal.

- This case highlights the importance of physicians being aware of the effect of co-administration of protease inhibitors (PIs) and antiretrovial regimes and corticosteroids.

- Early diagnosis and withdrawal of offending medication(s) should minimise complications from long-term steroid excess. 